\title{
DECISIONS
}

\section{Caring for a newly arrived Syrian refugee family}

\author{
Kevin Pottie MD MCISc, Christina Greenaway MD MSc, Ghayda Hassan PhD, Charles Hui MD, \\ Laurence J. Kirmayer MD
}

Fatima, Omar and Ruya, the Sarraf family, from Syria are newly arrived refugees to Canada. They have an appointment with their new family doctor. The family spent three years in a United Nations High Commissioner for Refugees refugee camp in Jordan and is now in Canada as part of a humanitarian resettlement program (Box 1). ${ }^{1-7}$

Fatima is 28 , Omar is 32 , and Ruya (which means "vision" or "dream" in Arabic) is 4 years old. They have no health or immunization records with them. In the office, Ruya appears quiet but anxious and is very reluctant to leave her mother's side. They all speak fluent Arabic, but none speak English or French. An interpreter arrives with the family.

\section{What intervention has the Sarraf family had before arrival in Canada?}

The Sarraf family will have had a medical history and a focused physical examination in accordance with the standard Immigration Medical Examination (Box 2). Testing includes a chest radiograph to rule out active pulmonary tuberculosis (TB) in those older than 11 years of age, a syphilis test and an HIV test for those 15 and older, and a urinalysis for children and adults. The results of these tests are the property of the Canadian government, and only certain results (e.g., for HIV testing) are communicated to settlement workers and public health officials in Canada.

\section{What preventive interventions should be considered at this visit?}

At this visit, an evidence-based health assessment should be provided for the Sarraf family, including discussion of vaccinations for vaccine-preventable diseases and some screening manoeuvres. These interventions are voluntary.

The following recommendations for preventive interventions have been adapted for newly arriving Syrian refugees who are asymptomatic, from the Canadian Collaboration for Immigrant and Refugee Health (CCIRH) guidelines ${ }^{2}$ and other guidelines (Box 2). They take into account the findings of European surveillance reports, because Europe has received nearly 600000 Syrian refugees in the past year alone. No major public health concerns have been reported thus far. However, because many of the refugees have faced prolonged and overcrowded shelter scenarios, scabies and head lice have been commonly reported. Rare cases of measles, cutaneous leishmaniasis and louse-borne fever have also been reported. ${ }^{8}$

The terms "recommend for" and "recommend against" are used when there is strong evidence that a particular intervention will be beneficial or not beneficial, respectively, in this population. For interventions that may have less clinical impact, we suggest that clinicians "consider" offering the intervention.

\section{Vaccine-preventable diseases}

Childhood vaccination coverage in Syria was greater than $90 \%$ before the war. The latest data from the World Health Organization (WHO) and UNICEF estimate that only $43 \%$ and $52 \%$ of Syrian refugee children have received their primary series of diphtheria-pertussis-tetanus vaccine and polio vaccine, respectively (prevalence sources available in Appendix 1, available at www.cmaj. ca/lookup/suppl/doi:10.1503/cmaj.151422/-/DC1). The CCIRH guidelines, ${ }^{2}$ the Canadian Immunization Guide and the Caring for Kids New to Canada guidelines (Box 2) recommend offering ageappropriate, provincially funded vaccinations to immigrant children, such as Ruya, with absent or uncertain vaccination records. Depending on age, these could include measles, mumps, rubella, diphtheria, tetanus, pertussis, Haemophilus influenzae $\mathrm{B}$ and polio.

Fatima and Omar also do not have immunization records. Therefore, similar to other adults $(\geq 18 \mathrm{yr})$ in this situation, they should receive a dose of the measles-mumps-rubella vaccine and a primary series for tetanus, diphtheria and polio, with a first dose that includes acellular pertussis vaccine. ${ }^{2}$ Vaccines may be given without prior serologic testing.
Competing interests: Kevin Pottie is lead consultant, Euro Health Group, Evidence Based Guidelines for Public

Health for the European Union/European Economic Area, European Centre for Disease Prevention and Control. Kevin Pottie, Christina Greenaway, Ghayda Hassan, Charles Hui and Laurence Kirmayer participated in the development of the Canadian Collaboration for Immigrant and Refugee Health guidelines. Charles Hui is the co-editor-in-chief of the Canadian Paediatric Society webbook, Caring for Kids New to Canada.

This article has been peer reviewed.

The clinical scenario is fictional.

Correspondence to: Kevin Pottie, kpottie@uottawa.ca

CMAJ 2016. DOI:10.1503 /cmaj.151422 
Limited data from the Mediterranean and Middle East regions suggest that most adolescents and young adults (83\%-97\%) are immune to varicella (Appendix 1). These data are also supported by a Canadian study in which nearly all young adults (96\%) originating from North Africa and the Middle East were found to be immune to varicella (Appendix 1). Because the varicella vaccine is not part of the routine vaccination program in Syria, we recommend varicella vaccination for Ruya and other children less than 13 years of age.

There may be a small risk of varicella outbreak in the Syrian refugee population, with susceptible adults and pregnant women at risk for severe disease. Therefore, for Fatima, Omar and other Syrian adults, clinicians may consider doing serologic testing for varicella and vaccinating those found to be susceptible. Vaccination without serology may be considered in certain contexts, but if implemented on a large scale, this would be more expensive.

\section{Tuberculosis}

In 2014, the WHO reported that the incidence of TB in Syria was low (17 per 100000 per year) (Appendix 1). Reported rates of active TB in Turkey and Lebanon were also low in 2014, at less than 20 per 100000 per year (Appendix 1). A study of Syrian refugees in Jordan in 2015 showed rates of TB of 12 per 100000 per year (Appendix 1). The CCIRH guidelines ${ }^{2}$ and the Canadian tuberculosis standards ${ }^{9}$ recommend offering screening for latent TB in groups of migrants when the incidence of TB in the country of origin is greater than 30 per 100000 per year. Given that the incidence of TB in Syria, neighbouring countries and among Syrians in the camps is below this threshold, we recommend against offering a Mantoux test to the Sarraf family and other Syrian refugees.

\section{Hepatitis $B$ virus}

The rate of chronic hepatitis B virus (HBV) infection in Syria is estimated to be 5.6\% (Appendix 1). The CCIRH guidelines ${ }^{2}$ and the Public Health Agency of $\mathrm{Canada}^{10}$ recommend that, when the rate of chronic $\mathrm{HBV}$ infection is $2 \%$ or higher, clinicians should order serologic tests for chronic hepatitis B and HBV immunity (hepatitis B surface antigen [HBsAg], hepatitis B core antibodies [anti-HBc] and hepatitis B surface antibodies [anti-HBs]) and vaccinate those found to be nonimmune. We recommend screening the Sarraf family and all Syrian refugees for HBV and vaccinating those found to be susceptible.

\section{Box 1: The Syrian context and the Canadian response ${ }^{1-7}$}

- The ongoing Syrian civil war ranks as the worst humanitarian catastrophe in modern times. More than half of the citizens of Syria have been forcibly displaced, with nearly 8 million people internally displaced and 4.5 million refugees, most having fled to the neighbouring countries of Jordan, Lebanon and Turkey. More than half of forcibly displaced people are children, and of these, nearly $75 \%$ are under the age of $12 .{ }^{1}$ As living conditions deteriorated in Turkish refugee camps in 2015, hundreds of thousands of Syrians fled to Europe. Thousands have died during this perilous journey.

- Repeated displacements have been a striking feature of the Syrian conflict, as frontlines keep shifting and formerly safe areas become embroiled in conflict. Experiences of violence are compounded by stressors, such as precarious living conditions, loss of family and supports, social isolation, discrimination and exploitation, and uncertainty about the future. ${ }^{1}$

- The Federal Government of Canada is implementing a rapid humanitarian resettlement of 25000 Syrian refugees in Canada over the coming months. Working with international organizations in Lebanon and Jordan, Canada is selecting and transporting refugees to cities across Canada.

- Health settlement refers to the provision of an evidence-based health assessment and the integration of refugees into the health system. Health practitioner networks to support refugees have been strengthened in Canada in recent years. Refugee-specific resources have been developed, including guidelines from the Canadian Collaboration for Immigrant and Refugee Health² and resources specifically for refugee children from the Canadian Paediatric Society. These networks, health advocacy groups (e.g., Canadian Doctors for Refugee Care) and provincial networks (e.g., Quebec Bilan de Santé des Réfugiés) are now working with municipal organizations on settlement.

- Refugees from Syria bring substantial positive human and social capital that can benefit Canadian society and contribute to economic growth, particularly when conditions of resettlement promote their resilience.

- Empathy, reassurance and advocacy are key clinical elements of the recovery process for refugees experiencing mental health issues. Emotional and social support can reduce the severity of symptoms of posttraumatic stress disorder and depression and facilitate the recovery process, although patients with persistent symptoms may need specific psychotherapeutic intervention. ${ }^{2}$ Access to safe and adequate housing, employment and income, family cohesion, and keeping parents and children together during and after the integration process may have strong protective health effects..$^{3,4}$ Conversely, difficult resettlement conditions, such as insecurity, economic difficulties, unemployment and social exclusion/isolation, can aggravate symptoms. ${ }^{5-7}$ 


\section{Hepatitis C virus}

The prevalence of hepatitis $\mathrm{C}$ virus (HCV) infection in the North Africa/Middle East regions and Syria is reported to be relatively low (about 1\%), with the exception of Egypt (Appendix 1). However, in the context of the conflict, trauma and a disrupted health care system, there may be increased risk of exposure to $\mathrm{HCV}$. Based on the uncertainty of HCV seroprevalence in the Syrian population and the availability of curative, albeit expensive treatment, clinicians may consider serologic tests for HCV infection for Fatima and Omar, as with all adults in this population.

\section{HIV}

The Immigration Medical Examination includes a test for HIV in all refugees who are 15 years of age and older, and this program links refugees who are seropositive to clinical treatment through public health. The HIV prevalence in the Middle East is less than $0.1 \%$ (Appendix 1). We do not recommend offering Fatima and Omar, or other adults, routine HIV testing on arrival.

\section{Strongyloides in immunocompromised patients}

The prevalence of infection with the intestinal parasite Strongyloides stercoralis in the Middle East region remains uncertain. Based on limited community-based studies, it was found to be relatively low $(<5 \%)$; however, the prevalence of strongyloidiasis appears to be highest in refugee populations (Appendix 1). Given the potential increased risk of $S$. stercoralis in the unsanitary living conditions of refugee camps, the potential benefit of preventing fatal disseminated strongyloidiasis in immunocompromised patients and the low risk of treatment, clinicians may consider offering serologic testing for $S$. stercoralis to Fatima, Omar and Ruya. ${ }^{2}$ More research could change this recommendation.

As per the CCIRH guidelines, we recommend against obtaining stool samples to test for ova and parasites in refugees who are asymptomatic. ${ }^{2}$

\section{Should the Sarraf family be screened for mental health problems?}

Members of the Sarraf family may experience mental health problems prompted by violence, displacement, the postemergency context or because of pre-existing mental disorders. ${ }^{1}$ For Syrian refugees, adaptation and recovery for both pre-existing mental disorders and those brought on by the difficulties they have experienced may be aided or impeded by the conditions of migration.

The most prevalent mental health problems among Syrian refugees include depression, prolonged grief disorder, posttraumatic stress disorder and various forms of anxiety disorders. ${ }^{1}$ Evidence of impairment of social functioning and/or a high level or long duration of suffering is essential for the diagnosis of common mental health disorders, such as posttraumatic stress

\section{Box 2: Resources for physicians caring for Syrian refugees}

- Immigration Medical Examination, Citizenship and Immigration Canada: www.cic.gc.ca/english/resources/publications/dmp-handbook/

- Canadian Immunization Guide, National Advisory Committee on Immunization: www.phac-aspc.gc.ca/publicat/cig-gci/index-eng.php

- Information on vaccination for children new to Canada: www.kidsnewtocanada.ca/screening/immunizations

- Caring for Kids New to Canada resource from the Canadian Paediatric Society: www.kidsnewtocanada.ca/ (English) and www.enfantsneocanadiens.ca/ (French)

- An evidence-based clinical e-checklist for immigrants from the Canadian Collaboration for Immigrant and Refugee Health (available in English and French): www.ccirhken.ca/ccirh/checklist_website/index.html

- Podcast series on immigrant health from the Cochrane Collaboration: http://community.cochrane.org/podcasts/issue/immigrant\%20health/577

- A review of culture, context, and the mental health and psychosocial well-being of Syrian refugees from the United Nations High Commissioner for Refugees: http://mhpss.net/?get = 250/culture_mental-health_syrians-final1.pdf

- Resources on refugee mental health from the Multicultural Mental Health Resource Centre: www.multiculturalmentalhealth.ca

- Citizenship and Immigration Canada population profile for Syria: http://rrlip.ca/userdata/files/201/EN\%20Syrian\%20Population\%20Profile.pdf

- Canadian Task Force on Preventive Health Care: http://canadiantaskforce.ca

- Network of physicians offering medical aid to Syrians: http://uossm-canada.org

- Syrian or Arab-speaking psychiatrists and psychologists offering mental health support to Syrian refugees worldwide: www.stmh.net 
disorder or depression, to avoid overdiagnosis in this group. ${ }^{1}$

Particularly vulnerable populations include unaccompanied Syrian refugee children, Syrians who have been victims of sexual and genderbased violence or torture and older Syrians or those with special needs. Sexual and genderbased violence and rates of torture have increased substantially because of the conflict and are associated with medical, psychological, social, economic and legal problems for refugees. ${ }^{11,12}$

Pushing for disclosure of traumatic events in well-functioning individuals who have survived torture or sexual and gender-based violence could be harmful; this increases the risk of inducing trauma, as well as raising issues of stigma and consequent ripple effects on family and community. ${ }^{2}$ We recommend against systematic screening for posttraumatic stress disorder but suggest that practitioners be alert for associated signs and symptoms (e.g., unexplained somatic symptoms, sleep disorders or mental health disorders, such as depression or panic disorder). ${ }^{2}$

\section{Are there other areas that should be specifically addressed in this visit?}

The family physician should document each patient's complaints, vital signs and visual acuity, and check for painful dental disease. ${ }^{2}$ In women like Fatima, unmet contraceptive and emergency contraceptive needs should be discussed, and a complete blood count test with differential to screen for anemia should be ordered. ${ }^{2}$ Clinicians should also consider seasonally recommended vac- cines, such as the influenza vaccine, and remain alert for sexually transmitted diseases, pregnancy, injuries, disability and interrupted treatments for conditions such as hypertension and diabetes.

\section{Are there other considerations that should be taken into account?}

Understanding culture-specific illness models and idioms of distress will allow better practitionerpatient communication, and in turn, this can inform culturally safe interventions to mobilize individual and collective resilience..$^{1,2}$

Over the centuries, the region that is now Syria was populated with people from a wide diversity of ethnic and religious backgrounds and has served as a haven for a variety of refugee groups fleeing persecution and conflict, including Armenians, Assyrians, Caucasians, Palestinians and Iraqis. Although most Syrians are considered Arabs, this is a term based on spoken language (Arabic), not ethnicity or religion. A review by the United Nations High Commissioner for Refugees provides information about cultural- and language-specific idioms of distress in this refugee group, as well as cultural and religious models of illness (available at www.unhcr.org/55f6b90f9.pdf). ${ }^{1}$

\section{Case revisited}

The family doctor began by preparing a CCIRH e-checklist for each member of the Sarraf family. The checklist (freely available at www.ccirhken. $\mathrm{ca} / \mathrm{ccirh} /$ checklist_website/) integrates recommendations from the CCIRH guidelines ${ }^{2}$ into a

\section{Box 3: Summary of recommendations for the care of Syrian refugees}

Syrian refugees have faced war crimes, human rights violations, poverty and prolonged displacement, which may have physical and mental health implications.

Access to safe and adequate housing, employment and income, family cohesion, and keeping parents and children together during and after the integration process may have strong protective health effects. Primary care physicians:

- Should not routinely screen for trauma but should remain alert for impairment of social functioning or high levels of suffering that may be related to posttraumatic stress disorder, depression or anxiety disorders, or exposure to war-related violence, and should refer patients to the appropriate services for assessment and follow-up.

- Should vaccinate all children and adults without a record of complete vaccination. Depending on age, these may include measles, mumps, rubella, diphtheria, tetanus, pertussis, Haemophilus influenzae B and polio.

- Should not offer testing for latent tuberculosis (TB) because the incidence of active TB in the Middle East region remains low.

- Should screen all children and adults for chronic hepatitis B virus infection and prior immunity, and vaccinate those who are susceptible.

- Should consider serologic testing for varicella in refugees 13 years of age and older and vaccinate those who are susceptible; many Syrians are likely immune.

- Should consider screening for hepatitis C virus infection; prevalence of this infection in Syrian refugees is currently uncertain, but war may have increased its prevalence.

- Should consider serologic testing for the intestinal parasite Strongyloides stercoralis but should not collect stool samples in asymptomatic patients. 
record tailored for newly arriving refugees and shows how the family doctor can address prevention and health concerns over a series of three to four visits. The checklist can also help bridge to recommendations from the Canadian Task Force on Preventive Health Care (Box 2).

The checklist suggests beginning with a patient-centred care approach, initially identifying any patient concerns. With this family, there were no medical concerns mentioned. The clinician asked Fatima and Omar about housing and other social needs and then offered them a health assessment.

The doctor collected background history from Fatima and Omar, conducted a focused exam on each family member that included visual acuity and dental screening, and offered vaccinations and blood testing as per the CCIRH guidelines. ${ }^{2}$

Fatima was assessed for pregnancy and unmet contraceptive needs, and other health screening for her was planned for future visits. The family doctor learned from Fatima that Ruya was born at the start of the war and her name represented her mother's hope for the family.

Upon further discussion, Omar turned out to have physical trauma to his left leg from the war that would benefit from crutches and additional assessments.

Ruya's anxious behaviour was observed throughout the visit and Omar interpreted this as a result of the bombardments and repeated displacement. The family doctor asked a few questions to ensure appropriate global development for Ruya and current family stability. The doctor also assessed the parents' individual level of personal or social functioning/impairment by asking questions around coping with past and current situations. ${ }^{13}$ A plan was made to further assess the family's difficulties in a primary care followup visit and later, if necessary, with psychological services or referral to an interdisciplinary pediatric mental health team. A referral to an orthopedic surgeon was tentatively planned, pending initial radiologic investigations of Omar's leg trauma.

Box 3 provides a summary of evidence-based interventions for Syrian refugees.

\section{References}

1. Hassan G, Kirmayer LJ, Mekki-Berrada A, et al. Culture, context and the mental health and psychosocial wellbeing of Syrians: a review for mental health and psychosocial support staff working with Syrians affected by armed conflict. Geneva: UNHCR; 2015. Available: www.unhcr.org/55f6b90f9.pdf (accessed 2015 Nov. 21).

2. Pottie K, Greenaway C, Feightner J, et al. Evidence-based clinical guidelines for immigrants and refugees. CMAJ 2011;183:E824-925.

3. Pottie K, Dahal G, Georgiades C, et al. Do first generation immigrant adolescents face higher rates of bullying, violence and suicidal behaviours than do third generation and native born? J Immigr Minor Health 2015;17:1557-66.

4. Beiser M, Hou F, Hyman I, et al. Poverty, family process, and the mental health of immigrant children in Canada. Am J Public Health 2002;92:220-7.

5. Procter NG, De Leo D, Newman L. Suicide and self-harm prevention for people in immigration detention. Med J Aust 2013;199: 730-2.

6. Kronick R, Rousseau D, Cleveland J. Asylum-seeking children's experiences of detention in Canada: a qualitative study. Am J Orthopsychiatry 2015;85:287-94.

7. Viruell-Fuentes EA, Miranda PY, Abdulrahim S. More than culture: structural racism, intersectionality theory, and immigrant health. Soc Sci Med 2012;75:2099-106.

8. Infectious diseases of specific relevance to newly arrived migrants in the EU/EEA. Stockholm: European Centre for Disease Prevention and Control; 2015. Available: http://ecdc. europa.eu/en/publications/Publications/Infectious-diseases-of -specific-relevance-to-newly-arrived-migrants-in-EU-EEA.pdf (accessed 2015 Dec. 15).

9. Greenaway C, Khan K, Schwartzman K. Tuberculosis surveillance and screening in high-risk populations. In: Canadian tuberculosis standards. 7th ed. Ottawa: Canadian Lung Association and Health Canada; 2013.

10. Primary care management of hepatitis B - quick reference (HBV-QR). Ottawa: Public Health Agency of Canada; [modified 2014]. Available: www.phac-aspc.gc.ca/publicat/hep/hbv-vhb/ index-eng.php (accessed 2015 Dec. 15).

11. United Nations Committee to End All Forms of Discrimination Against Women (CEDAW), 58th Session, Geneva, Switzerland July 2014. Seeking accountability and demanding change: a report on women's human rights violations in Syria before and during the conflict. New York: MADRE, The International Women's Human Rights (IWHR) Clinic at the City University of New York (CUNY) School of Law, The Women's International League for Peace and Freedom (WILPF); 2014. Available: www.madre.org/uploads/misc/1402077548 Syria CEDAWShadow\%20FINAL\%20ENG\%205.27.14\%20PDF.pdf (accessed 2015 Dec. 15).

12. Ellsberg M, Jansen HA, Heise L, et al.; WHO Multi-country Study on Women's Health and Domestic Violence against Women Study Team. Intimate partner violence and women's physical and mental health in the WHO multi-country study on women's health and domestic violence: an observational study. Lancet 2008;371:1165-72.

13. Kirmayer LJ, Narasiah L, Munoz M, et al. Common mental health problems in immigrants and refugees: general approach in primary care. CMAJ 2011;183:E959-67.

Affiliations: Bruyère Research Institute, Department of Family Medicine (Pottie); Department of Pediatrics, Division of Infectious Diseases (Hui), University of Ottawa, Ottawa, Ont.; Division of Infectious Disease (Greenaway); Division of Social and Transcultural Psychiatry (Kirmayer), McGill University, Montréal, Que.; Department of Psychology (Hassan), Université du Québec à Montréal, Montréal, Que.

Contributors: All of the authors contributed equally to the initial draft and revised the manuscript, approved the final version to be published and agreed to act as guarantors of the work.

Acknowledgements: The authors would like to thank Dr. Shauna Hacker for her help in editing the paper and the Canadian Collaboration for Immigrant and Refugee Health for its foundational systematic reviews and guidelines.

Decisions is a series that focuses on practical evidence-based approaches to common presentations in primary care. The articles address key decisions that a clinician may encounter during initial assessment. The information presented can usually be covered in a typical primary care appointment. Articles should be no longer than 650 words, may include one box, figure or table and should begin with a very brief description ( 75 words or less) of the clinical situation. The decisions addressed should be presented in the form of questions. A box providing helpful resources for the patient or physician is encouraged. 